\author{
Original
}

\title{
2-Imino-(3,4-dimethoxybenzyl) ethanesulfonic acid Schiff base anchored silver nanocomplex mediated by sugarcane juice and their antibacterial activities
}

\author{
Elias Emeka Elemike ${ }^{\mathrm{a}, *}$, Enock Olugbenga Dare ${ }^{\mathrm{b}, \mathrm{c}}$, Inyang David Samuel ${ }^{\mathrm{a}}$, \\ Jude Chinedu Onwuka ${ }^{b}$

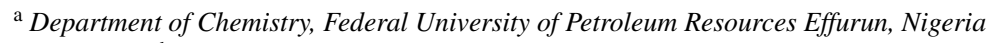 \\ ${ }^{\mathrm{b}}$ Department of Chemistry, Federal University Lafia, Nigeria \\ ${ }^{\mathrm{c}}$ Department of Chemistry, Federal University of Agriculture Abeokuta, Nigeria
}

Received 5 August 2015; accepted 28 December 2015

Available online 2 February 2016

\begin{abstract}
In this present investigation, 2-imino-(3,4-dimethoxybenzyl)ethane sulphonic acid was anchored on a silver nanoparticle mediated by sugarcane sap. The Schiff base was synthesized from 2-aminoethanesulphonic acid and 3,4-dimethoxybenzaldehyde under lemon juice catalyzed conditions while the nanoparticles were obtained by careful stirring of sugarcane sap and $1 \mathrm{mM} \mathrm{AgNO}$ in the ratio of 1:10 respectively at room temperature. The resulting nanocomplex was formed by gentle heating and stirring of the silver nanoparticles solution and the ligand at a temperature of about $80^{\circ} \mathrm{C}$ for $3 \mathrm{~h}$. The ligand, nanoparticles and nanocomplex were characterized using UV-vis spectrophotometer, scanning electron microscope, FT-IR and XRD machines. From the UV-vis results, surface plasmon bands (SPBs) were observed at $475 \mathrm{~nm}$ for the nanoparticle within $1 \mathrm{~h}$ of the reaction and $450 \mathrm{~nm}$ for the nanocomplex. The ligand exhibited absorption bands at $310 \mathrm{~nm}, 280 \mathrm{~nm}$ and $230 \mathrm{~nm}$ which are due to $\pi$ electron transitions within the chromophores. The strikingly broad nature of the SPBs especially in the nanoparticles revealed that the particles are kinetically favored, nucleate easily and are polydispersed and the blue shift observed in the nanocomplex suggested further reduction in the particle size therefore giving us a clue on how to tailor the products by tuning the raw materials. From the scanning electron micrographs, the morphologies and growth mechanisms revealed oriented attachment for the nanoparticles onwards digestive ripening for the nanocomplex. All the synthesized materials proved to be potential antibacterial agents as they showed great inhibition to the growth of some bacterial strains with the activity enhanced in the nanocomplex.

All Rights Reserved @ 2016 Universidad Nacional Autónoma de México, Centro de Ciencias Aplicadas y Desarrollo Tecnológico. This is an open access item distributed under the Creative Commons CC License BY-NC-ND 4.0.
\end{abstract}

Keywords: Nanocomplex; Surface plasmon bands; Antibacterial; Schiff base; Sugarcane

\section{Introduction}

Green nanotechnology is expanding its frontier in the world of science and technology and has been termed "the miracle of science" by some researchers as it continues to provide solutions and alternatives to technological, environmental, energy

\footnotetext{
* Corresponding author.

E-mail address: chemphilips@yahoo.com (E.E. Elemike).

Peer Review under the responsibility of Universidad Nacional Autónoma de México.
}

and health challenges (Mata, Palmer, Tejeda-Montes, \& Stupp, 2012). Nanostructures are the matter of interest for all applications of Nanotechnology wherein shape and size of the nanoparticles (NPs) determine their characteristic properties. Due to the growing demand for various nanoparticles, it is necessary to develop synthetic routes that are cost-effective and environment-friendly. The majority of the existing procedures used for nanoparticle synthesis rely upon physical and chemical methods which could introduce toxic and hazardous materials into the system (Ai, Biazar, \& Jafarpour, 2011; Mukherjee, Roy, \& Mandal, 2008) Moreover, the specific requirement for size and 


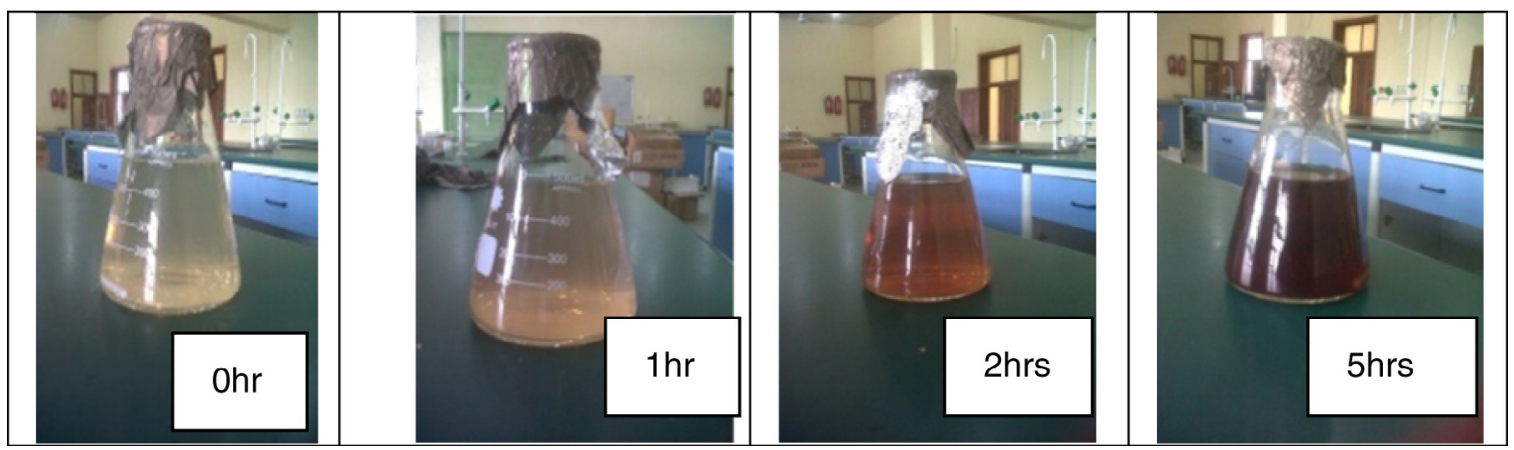

Figure 1. Color change of the silver nanoparticles at different times.

shape of nanoparticles cannot be met with the physico-chemical methods. Thus, biological methods involving microorganisms or plant extracts have shown to be more effective but in this recent research, there is a drift from the already known biological substrates to a new option which is plant sap. The integration of the principles of green chemistry to nanotechnology as regards to size manipulation of the nanoparticles is an unprecedented technique (Maryam, Niloofar, Ahmad, Fatemeh, \& Sassan, 2012).

Nanocomplexes of Schiff bases on the other hand are among the least areas of research in nanoscience that may hold great pharmaceutical applications. In our present world where new disease causing organisms such as Avian influenza, HIV/AIDS, Middle East respiratory syndrome (MERS), Ebola virus, etc., are discovered on daily basis, some being so tiny, posing difficulties in their disease treatment. It is reasonable to tackle these nano cum micro disease causing organisms with effective complex tools at nanoscale.

Kaushik in 2012, utilized grape juice to synthesis silver nanoparticles using different concentrations of the silver nitrate in the dark and at room temperature (Kaushik, 2013). In his work, the SPB was noticed at $450 \mathrm{~nm}$ and the particle size of the nanoparticles was $18-20 \mathrm{~nm}$. According to his reports, the nanoparticles exhibited high antimicrobial activities.

This present research focuses on using specific bio-molecules present in plant sap (sugarcane juice) as substrate to synthesize nanoparticles while anchoring it with Schiff base ligand to form a silver nanocomplex. The limitation of green silver nanoparticles and its antimicrobial activities vis-a-vis the strategies to improve the production of green antimicrobial drugs have also been discussed but not much information are available on nanocomplexes with Schiff base ligand. The development of nano-metal complexes by biological method is yet to be explored by researchers and on that note; it becomes a paramount objective in this study.

Moreover, in present times, clothing, respirators, household water filters, contraceptives, antibacterial sprays, cosmetics, detergent, dietary supplements, cell phones, laptop keyboards, and children's toys are among the products being marketed that purportedly exploit the antimicrobial properties of silver nanomaterials (Mohammad, Niloofar, \& Marjan, 2013). Apart from capitalizing on the antimicrobial potentials of the nanoform of silver, the focus upon the green methods of synthesis is of primary interest so as to counter the physiological and environmental peril associated with the use of chemicals for the fabrication and use of silver nanomaterials (Geoprincy, Vidhya Srii, Poonguzhali, Gandhi, \& Renganathan, 2013). Synthesis of green silver nanoparticles using plant extracts is a very simple and cost-effective way that satisfies the demand of the research community and simultaneously eliminates the possibility of environmental hazards; the plant sap seems to offer better opportunities though the results of this research will guide us appropriately. Our major aim therefore is to biologically synthesis silver nanoparticles using sugarcane juice while anchoring it with a Schiff base ligand.

The silver nanoparticles is synthesized using sugarcane sap while the ligand is a reaction between 3,4-dimethoxybenzaldehyde and 2-aminoethanesulfonic acid employing lemon juice as a green-catalytic approach.

\section{Materials and methods}

\subsection{Synthesis of silver nanoparticles using sugarcane (Saccharum officinarum) juice}

Fresh sugarcanes (Sa. officinarum) were collected from Okoripere village in Delta State, washed, peeled and chopped into smaller parts. It was further blended and filtered using Whatman filter paper and the filtrate used for the nanoparticle synthesis.

$1000 \mathrm{ml}$ of $1 \mathrm{mM} \mathrm{AgNO}_{3}$ was mixed with $100 \mathrm{ml}$ of surgarcane juice and stirred with a mechanical shaker at room temperature for $5 \mathrm{~h}$.

The colorless sample was noticed to turn into light wine-red and the color intensified with time as shown in Figure 1. At different times; $0 \mathrm{~h}, 1 \mathrm{~h}, 2 \mathrm{~h}$, and $5 \mathrm{~h}$ while stirring the solution at room temperature, they were sampled and analyzed using UV-vis spectrophotometer (Elemike et al., 2014; Sepideh, Seyedeh, Seyed, \& Soheila, 2012). It was observed that the surface plasmon band appeared at $475 \mathrm{~nm}$ after $1 \mathrm{~h}$ of reaction, showing the formation of silver nanoparticles and the spectra shown in Figure $2 b$.

\subsection{Preparation of 2-imino-(3,4-dimethoxybenzyl) ethanesulfonic acid Schiff base}

In a $50 \mathrm{ml}$ Erlenmeyer flask, 0.01 mole (1.710 g) 3,4-dimethoxybenzaldehyde and 0.01 mole (1.255 g) 2aminoethanesulfonic acid was reacted in a $30 \mathrm{ml}$ of deionised 

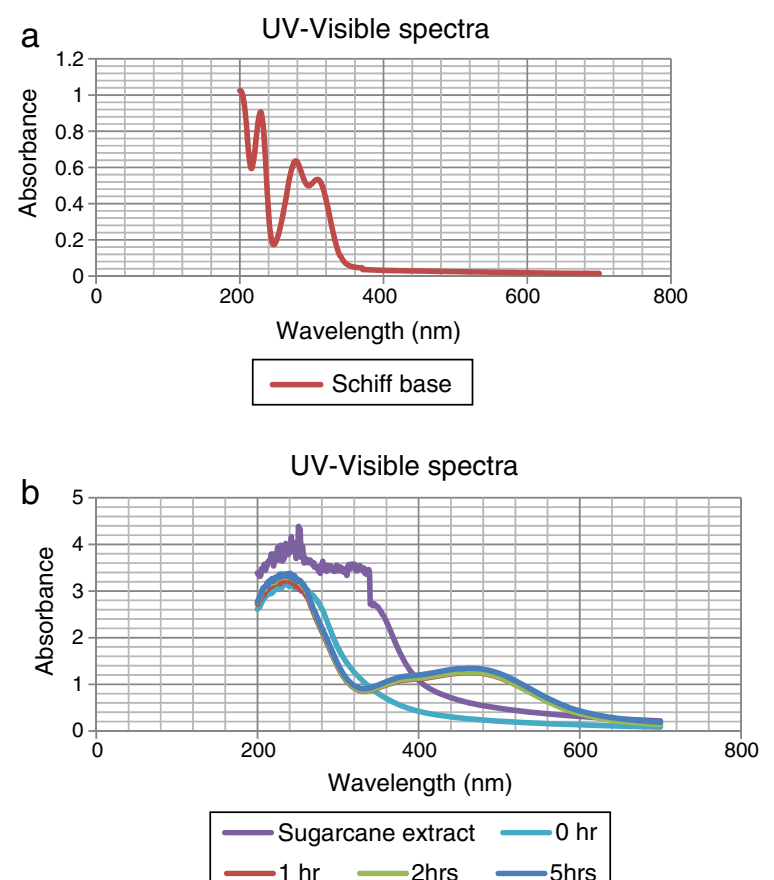

C

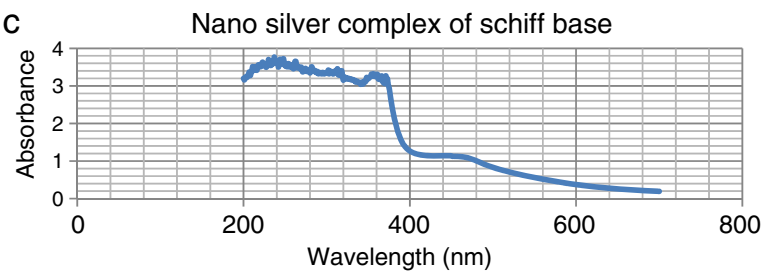

Nano silver complex of schiff base

Figure 2. UV-vis spectra of (a) Schiff base ligand, (b) silver nanoparticles and (c) silver nanocomplex.

water/15 ml ethanol media mixture. Three drops of lemon juice was added as catalyst. The reacting mixture was stirred while heating at about $70^{\circ} \mathrm{C}$ for $3 \mathrm{~h}$ (Ugwu \& Okoro, 2014). Light brown solution was observed, filtered and was left to stand for 2 days and crystals formed thereafter. The presence of the lemon juice catalyzed the reaction as without it, the solution could not crystallize for some days under observation (Scheme 1).

\subsection{Preparation of nano-silver complex mediated by the Schiff base}

Synthesis of the silver nanocomplex was done by anchoring the ligand as prepared above on the synthesized silver nanoparticles (Sujarania, Sironmani, \& Ramu, 2012).

The ligand in a 30:15 $\mathrm{ml}$ water-ethanol ratio respectively was mixed with $10 \mathrm{ml}$ of the aqueous silver nanoparticles solution prepared using sugarcane juice and little quantity of lemon juice added as catalyst. The entire solution was gently stirred for an hour at room temperature. Afterwards, it was left to stand for 2 days and the resultant light brown crystals were dried and characterized.

\subsection{Instrumental characterization}

The absorption spectrum of the materials was measured on a T-60 UV-vis spectrophotometer and the spectra shown in Figure $2 \mathrm{a}-\mathrm{c}$. The phase identity and crystalline size of the nanoparticles and nanocomplex were characterized by X-ray diffractometer and the representative plot shown in Figure 4. Morphological features were studied by using Hitachi-7000 scanning electron microscope (SEM), and the functional groups and possible bioreductants determined by the 8500S Fourier transform infra-red spectrophotometer.

\subsection{Antibacterial analysis}

The synthesized ligand, nanoparticles and nanocomplex were screened against some clinical bacteria isolates obtained from Standard Diagnostics Laboratory Effurun using Agar well dilution method. Bacterial cultures were prepared and different concentrations of the test samples and the control drug (Ciprofloxacin) were equally prepared up to a minimum concentration of $20 \mu \mathrm{g} / \mathrm{ml}$ using standard methods (Nelson et al., 2007; Prabakaran, Subha, Thennarasu, \& Merinal, 2012). The growth of the microorganisms was monitored and the results are shown in Table 1 and Figure 5.

\section{Results and discussion}

The substrate or biomolecules used for synthesis of nanoparticles play very important role in the surface reactions, size and morphology of nanoparticles. As is well known, biomolecules<smiles>COc1ccc(C=O)cc1OCCOCCOCCO</smiles>

3,4-dimethoxybenzaldehyde

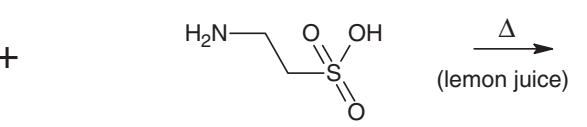

2-aminoethanesulfonic acid

(Taurine)

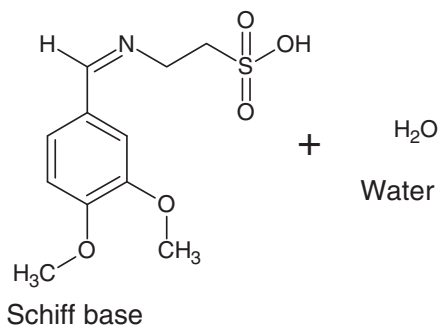

(Proposed structure)

Scheme 1. Proposed structure of the Schiff base ligand. 


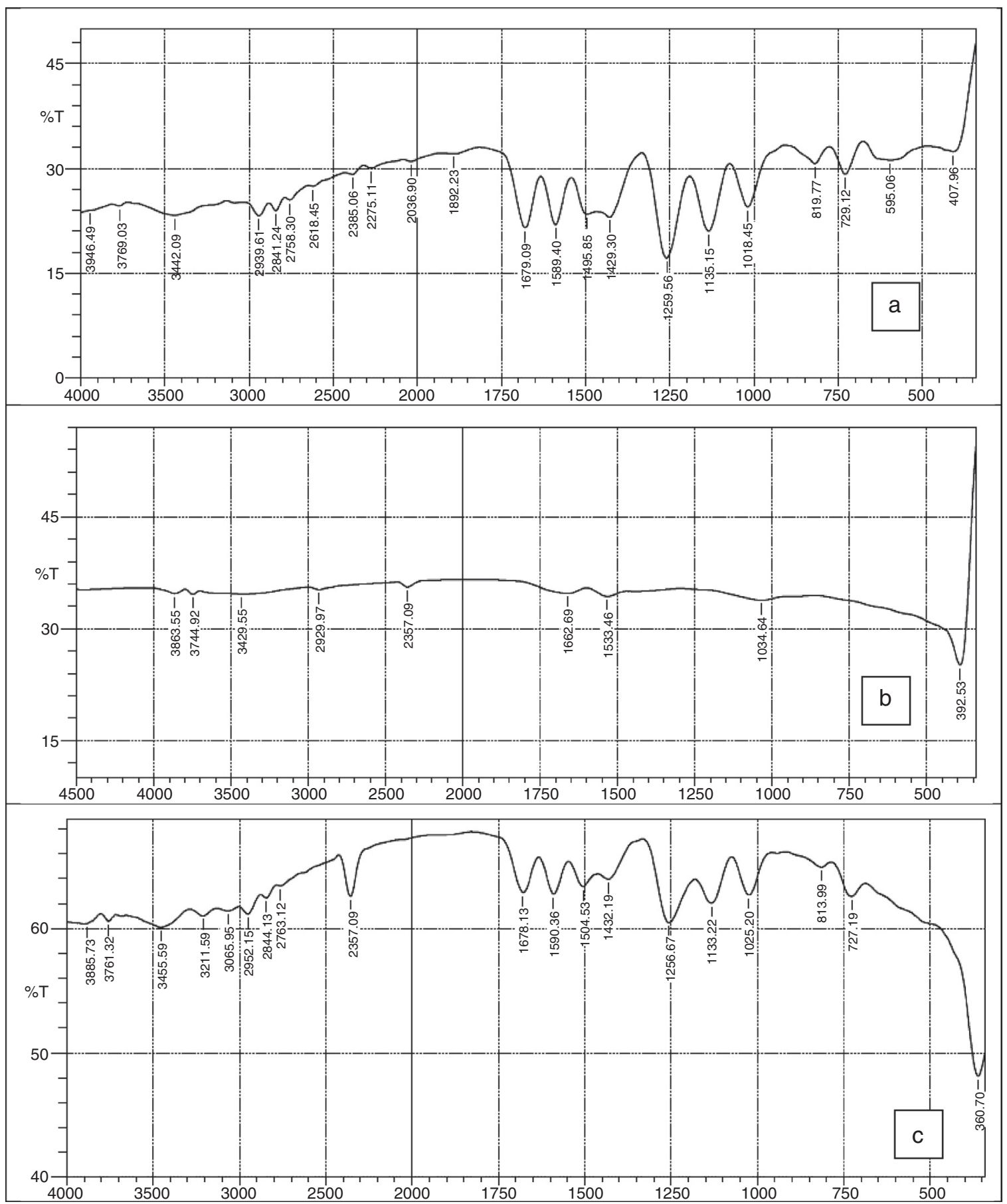

Figure 3. FTIR spectra of (a) Schiff base ligand, (b) sugarcane mediated silver nanoparticles and (c) silver nanocomplex.

can carry on slow kinetics to self-reduce metal precursors and develop stable coating layers to avoid particle aggregation (Renquan, Dapeng, Daxiang, Zhongyang, \& Lin, 2012).

\subsection{Uv-vis spectra analysis}

From Figure 1, it is seen that the color started changing gradually to wine-red and this was confirmed by surface plasmon bands displayed by the nanoparticles within $1 \mathrm{~h}$ of the reaction at a wavelength of about $475 \mathrm{~nm}$. This wavelength persisted even at the subsequent periods of sampling showing that the substrate (sugarcane juice) acts as both reducing and stabilizing agent as shown in Figure $2 b$.

The major component of sugarcane juice that has caused the bio-reduction of $\mathrm{Ag}^{+}$to $\mathrm{Ag}^{0}$ is glucose and other components such as proteins, minerals etc. which are in minor quantities. Sucrose is the major component of cane juice but may not have affected the reduction since it is not a reducing agent. In fact, the same molecular mechanisms that give antioxidant properties to these molecules must have promoted the reduction of 
Table 1

Antibacterial results of the synthesized ligand and nanocompounds.

\begin{tabular}{|c|c|c|c|c|c|c|c|c|}
\hline \multirow[t]{2}{*}{ Isolates } & \multicolumn{4}{|l|}{$40 \mu \mathrm{g} / \mathrm{ml}$} & \multicolumn{4}{|c|}{$20 \mu \mathrm{g} / \mathrm{ml}$} \\
\hline & Control & Ligand & Silver nanoparticles & Nanocomplex & Control & Ligand & Silver nanoparticles & Nanocomplex \\
\hline Staphylococcus aureus & -- & -- & -- & -- & - & - & - & -- \\
\hline Staphylococcus aubeus & -- & -- & -- & -- & - & - & - & -- \\
\hline Escherichia coli & -- & -- & -- & -- & - & - & - & -- \\
\hline
\end{tabular}

$\mathrm{Ag}^{+}$ions to $\mathrm{Ag}$ atoms. The exact mechanism of the extracellular biosynthesis of metal nanoparticle is not well understood. However, two possible mechanisms have been hypothesized. These are; hydrogen abstraction, due to the $\mathrm{OH}$ groups in the sucrose molecules and redox reaction of nicotinamide adenine dinucleotide (NADH) coenzyme which works as an electron shuttle to neutralize $\mathrm{Ag}^{+}$ion (Labrenz et al., 2000; Roh et al., 2001; Swarnalatha, Christina, Shruti, \& Payas, 2012). For the formation of silver nanoparticles, the sample changed its visual appearance within $1 \mathrm{~h}$ after addition of the extract, indicating that a reduction reaction took place. Initially, the reacting mixture was slightly brownish liquid; as the reaction proceeded, the solution became deep wine-red showing the strong absorption of visible light due to excitation of the nanoparticle surface plasmons (Amendola, Bakr, \& Stellacd, 2010; Ericka et al., 2012; Hartland, 2011; Kwon, Lee, Wark, \& Lee, 2012; Ray, 2010). Figure $2 \mathrm{~b}$ shows that the SPBs was formed within $1 \mathrm{~h}$ and stabilized even after the 5 th hour of sampling. The sugarcane extract did not give bands within the range of $400-500 \mathrm{~nm}$ which is a clear evidence that it is not nanoparticles. The surface plasmon absorption in the nanoparticles is due to the collective oscillation of the free conduction band electrons which is excited by the incident electromagnetic radiation. This type of resonance is seen when the wavelength of the incident light far exceeds the particle diameter (Naika et al., 2015).

The nature of the broad band shows that the nanoparticles are polydisperse and have greater distribution of particle size (Hale, Maddox, Shapter, \& Voelcker, 2005). Moreover, the constant nature of the bands in the subsequent reaction times proves the

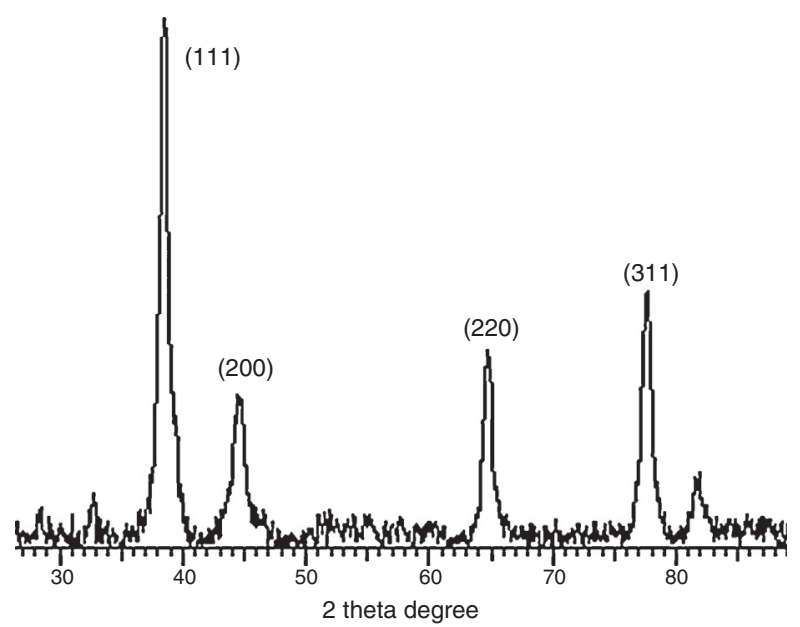

Figure 4. Representative XRD plot of the Ag nanocomplex. stable nature of the nanoparticles formed thereby reassuring the substrate as a good bio-reducing and stabilizing agent.

In the case of the Schiff base ligand, absorption bands were observed at $310 \mathrm{~nm}, 280 \mathrm{~nm}$ and $230 \mathrm{~nm}$ which could be attributed to the chromophores in the ligand.

In Figure 2c, the spectra of the nanocomplex showed a broad peak with a maximum absorption at $450 \mathrm{~nm}$. The blue shift in the surface plasmon bands as compared to Figure $2 \mathrm{~b}$ is an indication of smaller colloids equally supported by the broader peak which also indicates a greater distribution of the particle size.

\subsection{FTIR spectra}

Figure $3 \mathrm{a}-\mathrm{c}$ shows the FTIR spectra of 2-imino-(3,4dimethoxybenzyl) ethanesulfonic acid Schiff base, silver nanoparticles and nanocomplex. The absence of spikes above $3300 \mathrm{~cm}^{-1}$ in Figure 3 a show that the primary amine has formed an imine in the ligand and cannot be absorbed within that frequency range (Wade, 2006). The weak absorption around $3442 \mathrm{~cm}^{-1}$ could be attributed to some water molecules. The strong absorption peaks at 2939 and $2841 \mathrm{~cm}^{-1}$ for the ligand and $2357 \mathrm{~cm}^{-1}$ for the nanocomplex indicates the $\mathrm{C}-\mathrm{H}$ stretching vibrations. The imine $(\mathrm{C}=\mathrm{N})$ functional group absorbed strongly at $1679 \mathrm{~cm}^{-1}$ for the ligand and at $1678 \mathrm{~cm}^{-1}$ for the nanocomplex. The presence of the benzene ring conjugated to imine group in both the ligand and nanocomplex were noticed at 1589 and $1590 \mathrm{~cm}^{-1}$ respectively (Okoli, Adewuyi, Zhang, Diagboya, \& Guo, 2014). The striking feature of $\mathrm{SO}_{3} \mathrm{H}$ group was shown by the absorptions at $1259 \mathrm{~cm}^{-1}$ and $1256 \mathrm{~cm}^{-1}$ for the ligand and nanocomplex respectively. The $\mathrm{C}-\mathrm{O}$ stretching vibrations which is characteristic of ether groups were observed at $1018,1135 \mathrm{~cm}^{-1}$ for the ligand and $1025,1133 \mathrm{~cm}^{-1}$ for the nanocomplex. The strong absorption at $360 \mathrm{~cm}^{-1}$ in the nanocomplex which is absent in the Schiff base ligand is a strong indication of presence of silver metal. Figure $3 \mathrm{~b}$ which shows the spectra of the silver nanoparticles has weak absorptions at $3386 \mathrm{~cm}^{-1}$ which indicates $\mathrm{O}-\mathrm{H}$ molecules. The other absorptions at $1650 \mathrm{~cm}^{-1}$ and $1041 \mathrm{~cm}^{-1}$ are attributed to $\mathrm{C}=\mathrm{O}$ bonds probably due to glucose molecules while the band at $386 \mathrm{~cm}^{-1}$ represents the silver metal (Morrison \& Boyd, 2002).

\subsection{Powder X-ray diffraction analysis}

The XRD diffraction pattern of dry nanosilver powder in Figure 4 shows a crystalline nanocomplex of about $15 \mathrm{~nm}$ with the peaks suggesting high purity of the compound. The other observed peak and noise were probably related to the effect 

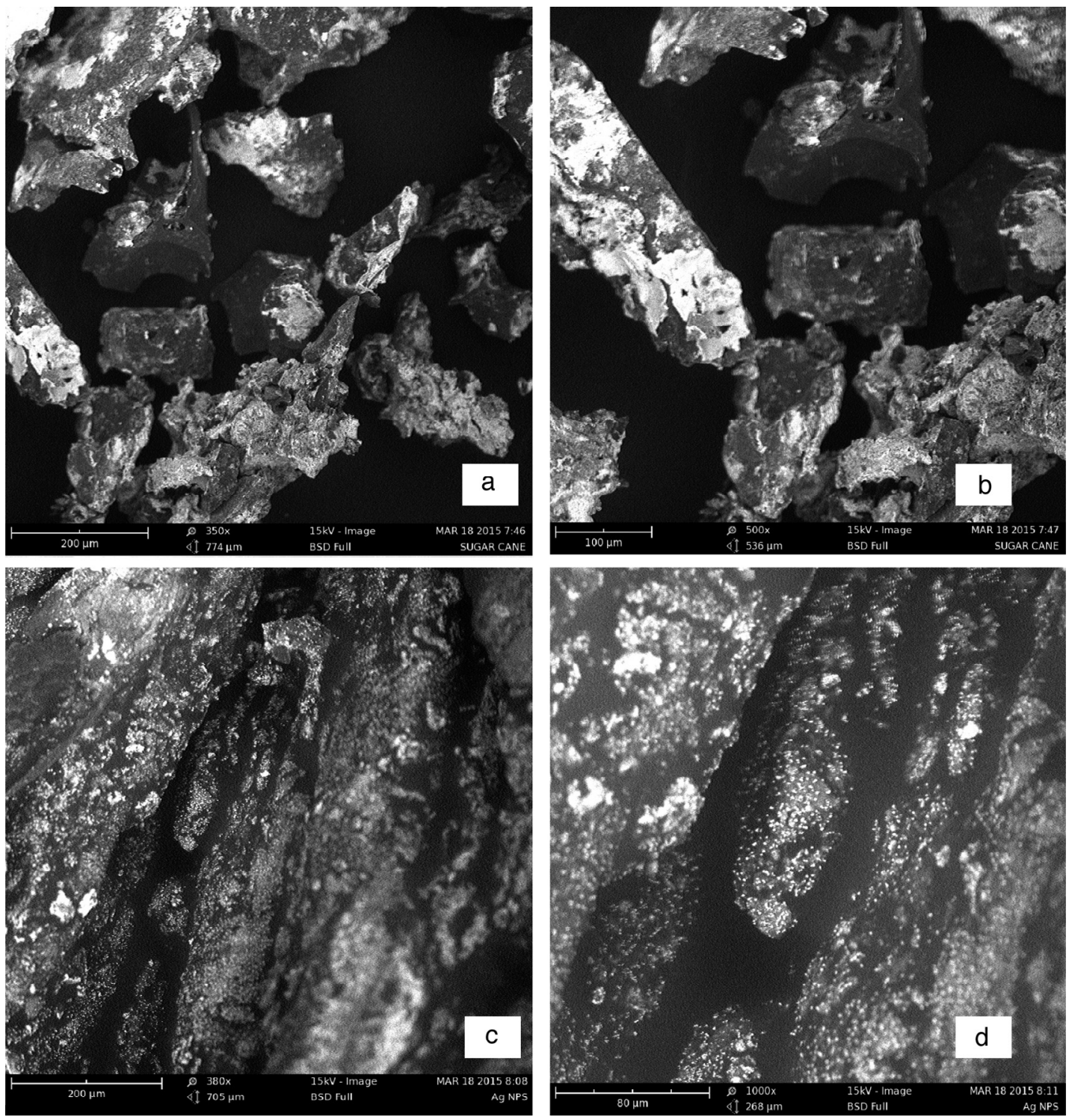

Figure 5. Scanning electron micrographs of silver nanoparticles $(a, b)$ and nanocomplex $(c, d)$ in different magnifications.

of nanosized particles and the presence of various crystalline biological macromolecules in the sugarcane sap. The obtained results illustrate that silver ions had indeed been reduced to $\mathrm{Ag}$ by the sap and ligand under reaction conditions (Forough \& Farhadi, 2010; Rajesh, Raja, Rathi, \& Sahayaraj, 2012). The nanoparticles showed higher particle sizes of about $25-30 \mathrm{~nm}$.

\subsection{Scanning electron microscopy (SEM) analysis}

The SEM showed interesting morphologies both for the sugarcane nanoparticles and the nanocomplex as shown in Figure 5a-d. Figure 5a showed an intermediate morphology between cube and cone that may have potential applications as molecular grippers in nanomedicine.

Based on the micrographs and supporting UV-vis spectra, the early stages of growth of the nanoparticles could be seen to follow the oriented attachment (OA) since the nanocrystallites grow on the already existing nanocubes followed by surface crystallization and a phase transformation to an intermediate cube-cone nanostructures as shown in Figure 5a.

The OA mechanism has attracted preponderant interests due to its fundamental role in designing and exploring materials with size and morphology controllability (Zhang, Huang, \& Lin, 2010). Peculiar structures and morphologies displayed by the nanosystems are due to reduction in surface energy and coherent crystallographic orientation which provides a route for the incorporation of defects like stacking faults, twins and misorientation.

The anchoring of ligand on the nanocubes and cones seems to affect the crystal growth kinetics of the system thereby giving rise to the small spherical nanoparticles exhibited by the nanocomplex as shown in Figure $5 \mathrm{c}$ and $\mathrm{d}$. The introduction of the organic ligand which has unstable surface adsorption property could be destroyed or desorbed in the hydrothermal 

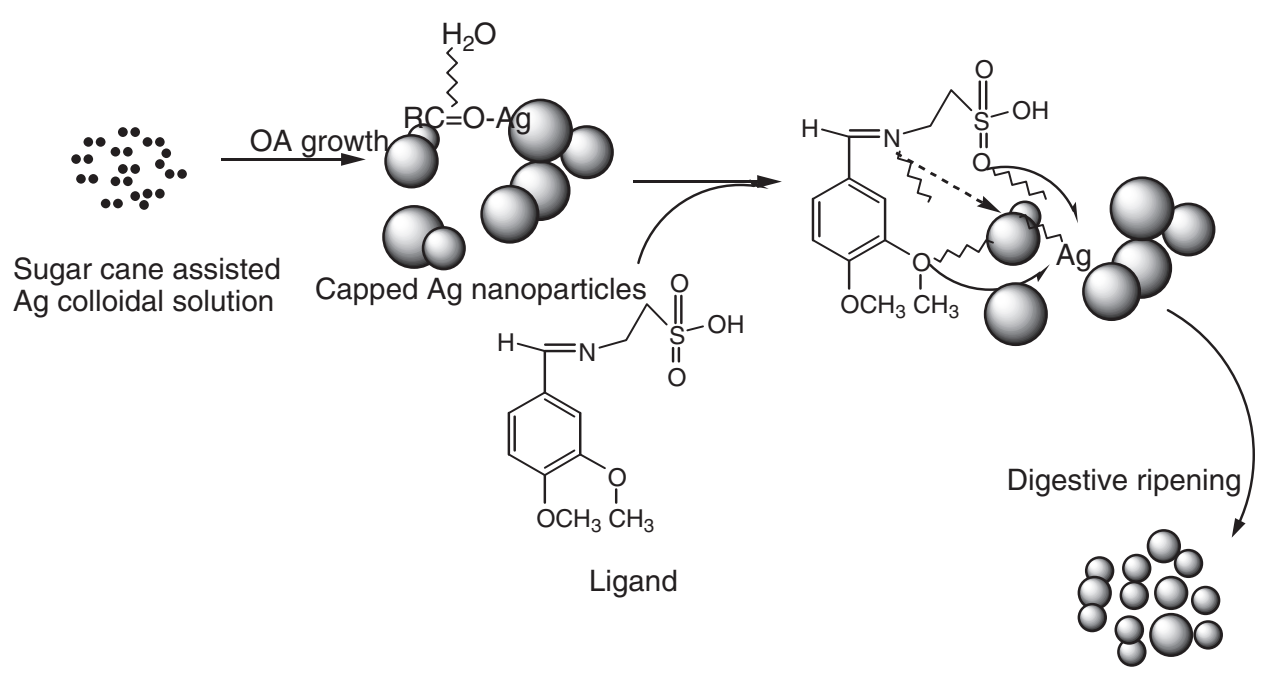

Spherical nanocomplex

Scheme 2. Schematic diagram of possible reaction pathway and growth mechanism of the nanoparticles and nanocomplex.

medium. Evidently, the appearance of the small spherical particles in the nanocomplex indicates that the mass transportation was incessant. There was further crystallization which extended inwards at the expense of the ligand nutrients creating large interior space and surface area (Greer, 2014). This could equally be supported by the UV-vis spectra shown in Figure 2a and c where there was a blue shift from $475 \mathrm{~nm}$ in the nanoparticles to $450 \mathrm{~nm}$ in the nanocomplex. It would be expected that the Ostwald ripening should have set in since the ligand molecules may not be able to penetrate into the core region of the nanosystems but based on the evidence from the results, digestive ripening which is the inverse of Ostwald ripening could be suggested as the growth mechanisms (Greer, 2014). The process of formation is controlled by the surface energy of the particle within solution where the larger particles redissolve and the smaller ones grow (Nguyen, Maclean, \& Mahiddine, 2014). Moreso, the diffusion of the ligands along the surface of the nanosystems could have changed the shape of the particle. This situation occurs under specific conditions where the energy of the ligands within the solution is probably low, forming a gap between the shell and the core particle (Yanjun et al., 2012).

\subsection{Growth kinetics; oriented attachment onwards digestive ripening}

The type of kinetics displayed by the sugarcane nanoparticles based on the spectral and micrograph evidence is a typical oriented attachment. Moreover, this experimental result is in consonance with the theoretical as well as other experimental studies which suggest that growth of nanoparticles can be greatly influenced by surface reactions thereby proceeding from a diffusion controlled mechanism onwards to oriented attachment (Dare et al., 2015). It could be suggested that the surface adsorption of the capping organic molecules (such as sucrose) present in the sugarcane sap, which was not involved in bioreduction could have been purely responsible for the exclusive $\mathrm{OA}$ growth as shown in Scheme 2. According to Penn, OA mechanism is due to the degree of electrostatic interactions such as the Vander waal forces which consequently determines the kinetic rate constant (Penn \& Banfield, 2004). While Ribeiro, Lee, Longo, and Leite, 2005, considers the diffusion and coagulation of the colloids thereby suggesting that the viscosity of the medium played a significant role in the OA mechanism, which is governed by an inverse proportional relationship with respect to the rate constant. In the above-mentioned models, only primary particles are assumed to combine to give secondary particles and the reaction stops; but experimentally, the OA mechanism has proven that growth behavior can go beyond collision and reaction of molecules. The nanocrystals may be capped with easily destroyed and desorbed organic ligands with the coalescence of some multilevel particle being neglected. This mechanism can be likened to the classical Smoluchowski equation which is a limiting case of aggregation that involves monomer-monomer and monomer-multimer reactions neglecting the multimer-multimer reactions.

The incorporation of organic ligands into the nanoparticle medium seems to arrest the OA growth process and introduces the digestive ripening. The polydisperse nanocrystal lattices emanating from the initial sugarcane mediated system was modified upon refluxing with ligand molecules leading to digestive ripening and nucleating the colloid at the phase boundary (Yijun, Deepa, Christopher, \& Kenneth, 2013). Unlike the well-known Ostwald ripening in which large particles grow at the expense of small particles, this process narrows the distribution by sharing material among different sizes of particles until a thermodynamically stable size segregation can further select the specific particle size (Lin, Sorensen, \& Klabunde, 2000). Many works have been reported on the stabilization of nanoparticles suggesting that control may be due to thermodynamics other than the kinetics of nucleation and crystal growth (Chikan \& Kelley, 2002). In this work, the nanoparticle size resulted from a combination of the ligand-silver binding energy and the surface free 


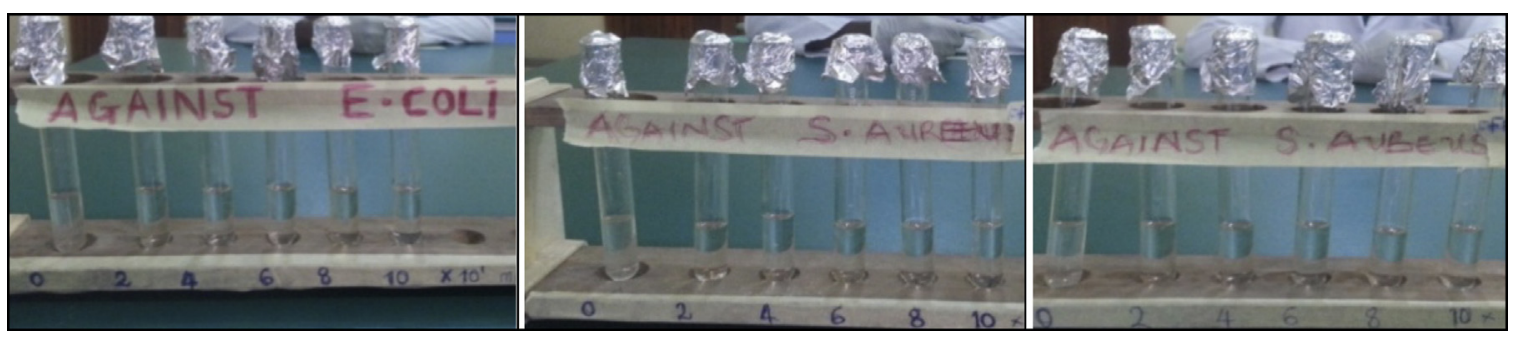

Figure 6. Aqeous solution of the synthesized ligand, nanoparticles and nanocomplex with the microbes.

energy of the particles to reach the minimum energy of the whole system. The ligand-silver binding energy favors smaller particles with larger surface areas, while the surface free energy favors larger particles with smaller surface curvature. Therefore, these two effects oppose each other and led to a minimum energy with a thermodynamically favored size for each silver-ligand colloid system.

From the results, we could draw a conclusion that iminosulphonic acid does play a significant role as a capping ligand in stabilizing the nanocomplex and giving smaller particle sizes.

\subsection{Antibacterial evaluation of the ligand, Ag NPs and the nanocomplex}

The ligand, silver nanoparticles and the nanocomplex were screened against Escherichia coli, Staphylococcus auerus and $S$. aubeus bacterial strains and the results are presented in Table 1. Using Agar well dilution method, the ligand, Ag Nps and nanocomplex showed significant antibacterial activity on all the three bacterial strains. Nano-silver inside bacterial cells disrupts the biochemical processes by binding with DNA molecules which leads to disordering of the helical structure by crosslinking within and between the nucleic acid strands (Kim, Cho, Ryu, \& Choi, 2000). Indirect effects through changes in the surrounding charge environment also have an impact on the effectiveness of nanoparticulate metals against microorganisms (Stohs \& Bagchi, 1995). Moreover, the silver released from the nanoparticles get attached to the negatively charged bacterial cell wall, rupturing it thereby leading to protein denaturation and finally causes cell death (Sondi \& Sondi, 2004). It is evident from Table 1 and Figure 6, that the growth of the three bacterial strains was severely inhibited by the nanocomplex than the ligands and nanoparticles.

\section{Conclusion}

From the research work, we have synthesized a Schiff base derived from 3,4-dimethoxybenzaldehyde and 2aminoethanesulfonic acid and its silver nanocomplex. The formation of the nanocomplex, the ligand and the silver nanoparticles were analyzed using UV-vis spectrophotometer, FTIR, XRD and SEM. The ligand introduced digestive ripening on the nanoparticles framework thereby establishing stable spherical structures with high surface area and mechanical strength. The ligand with typical imine sulphonic acid group act as useful capping and stabilizing agent for silver nanoparticles while the refluxing close to the boiling point of water effected good digestive ripening. The antibacterial activities results shows that the nanocomplex has enhanced antibacterial properties on E. coli, S. aureus and S. aubeus than its parents Schiff base and nanoparticles. The greater efficacy of the nanocomplex is positively modified upon coordination of the ligand with the nano-silver metal. The established structure in this research therefore acts as self sacrificial templates to fabricate other structural nanosystems with enhanced functionalities. There is scarce information on the synthesis of silver nanocomplex. The results of this study have furnished us with some information but we need more analysis and further research to establish the unfolding success believed to be associated with this emerging bionanoparticulate inorganic system.

\section{Conflict of interest}

The authors have no conflicts of interest to declare. All authors participated in this research and have endorsed the publication of this work.

\section{Acknowledgments}

The authors wish to thank the Vice chancellor, Federal University of Petroleum Resources Effurun, Prof Akii Ibhadode for the excellent drive toward research. Mr Bawa Hamza and other technologists in the department of chemistry FUPRE are also greatly acknowledged in this work for their immense contribution toward the antibacterial analysis.

\section{References}

Ai, J., Biazar, E., \& Jafarpour, M. (2011). Nanotoxicology and nanoparticle safety in biomedical designs. International Journal of Nanomedicine, 6 , 1117-1127

Amendola, V., Bakr, O. M., \& Stellacd, F. (2010). A study of the surface plasmon resonance of silver nanoparticles by the discrete dipole approximation method: Effect of shape, size, structure, and assemble. Plasmonics, 5, 85-97.

Chikan, V., \& Kelley, D. F. (2002). Size dependent spectroscopy of $\mathrm{MoS}_{2}$ nanoclusters. Journal of Physical Chemistry B, 106, 3794-3804.

Dare, E. O., Oseghale, C. O., Labulo, A. H., Adesuji, E. T., Elemike, E. E., Onwuka, J. C., et al. (2015). Green synthesis and growth kinetics of nanosilver under bio-diversified plant extracts influence. Journal of Nanostructure in Chemistry, 5, 85-94.

Elemike, E. E., Oseghale, C. O., Chuku, A., Labulo, A. H., Owoseni, M. C., Mfon, R., et al. (2014). Evaluation of antibacterial activities of silver nanoparticles green-synthesized using pineapple leaf. Micron, 57, 1-5. 
Ericka, R., Ramon, I., Rosa, N., Ronaldo, H., Judith, T., Claudia, I., et al. (2012). Synthesis of silver nanoparticles using reducing agents obtained from natural sources (Rumex hymenosepalus extracts). Springer Open Journal, 3, $1-5$.

Forough, M., \& Farhadi, K. (2010). Biological and green synthesis of silver nanoparticles. Turkish Journal of Engineering and Environmental Sciences, 34, 281-287.

Geoprincy, G., Vidhya Srii, B. N., Poonguzhali, U., Gandhi, N. N., \& Renganathan, S. (2013). A review on green synthesis of silver nanoparticles. Asian Journal of Pharmaceutical and Clinical Research, 6(1), 8-12.

Greer, H. F. (2014). Non classical crystal growth of inorganic and organic materials. Material Science and Technology, 30(6), 611-625.

Hale, P. S., Maddox, L. M., Shapter, J. G., \& Voelcker, N. H. (2005). Growth kinetics and modeling of $\mathrm{ZnO}$ nanoparticles. Journal of Chemical Education, 82(5), 775-778.

Hartland, G. V. (2011). Optical studies of dynamics in noble metal nanostructures. Chemical Reviews, 111, 3858-3887.

Kaushik, R. (2013). Green synthesis of silver nanoparticles by using grape fruit extract: Characterization of the particles \& study of antibacterial activity. Research Journal of Pharmaceutical, Biological and Chemical Sciences, 4, 1271-1276.

Kim, J. H., Cho, H., Ryu, S., \& Choi, M. (2000). Effects of metal ions on the activity of protein tyrosine phosphatase VHR: Highly potent and reversible oxidative inactivation by $\mathrm{Cu}^{2+}$ ion. Archives of Biochemistry and Biophysics, 382, 72-80

Kwon, M. J., Lee, J., Wark, A. W., \& Lee, H. J. (2012). Nanoparticle-enhanced surface plasmon resonance detection of proteins at molar concentrations: Comparing different nanoparticle shape and sizes. Analytical Chemistry, 84, 1702-1707.

Labrenz, M., Druschel, G. K., Thomsen, E. T., Gilbert, B., Welch, S. A., \& Kemner, K. M. (2000). Formation of sphalerite $(\mathrm{ZnS})$ deposits in natural biofilms of sulfate-reducing bacteria. Science Journal, 1, 744-747.

Lin, X. M., Sorensen, C. M., \& Klabunde, K. J. (2000). Digestive ripening, nanophase segregation and superlattice formation in gold nanocrystal colloids. Journal of Nanoparticle Research, 2(2), 157-164.

Maryam, M., Niloofar, R., Ahmad, R. S., Fatemeh, N., \& Sassan, R. (2012). Extracellular production of silver nanoparticles by using three common species of dermatophytes: Trichophyton rubrum, Trichophyton mentagrophytes and Microsporum canis. Iranian Biomedical Journal, 16(1), 52-58.

Mata, A., Palmer, L., Tejeda-Montes, E., \& Stupp, S. (2012). Design of biomolecules for nanoengineered biomaterials for regenerative medicine. Methods in Molecular Biology, 811, 39-49.

Mohammad, M., Niloofar, Y., \& Marjan, M. (2013). Antibacterial properties of nanosilver finish cellulose fabric. Journal of Nanostructure in Chemistry, 3, 43.

Morrison, R. T., \& Boyd, R. N. (2002). Organic chemistry (6th ed., pp. 590-592). Prentice and Hall India.

Mukherjee, P., Roy, M., \& Mandal, B. P. (2008). Green synthesis of highly stabilized nanocrystalline silver particles by a non-pathogenic and agriculturally important fungus T. asperellum. Nanotechnology, 19(7), 075103-075110.

Naika, H. R., Lingaraju, K., Manjunath, K., Danith, K., Nagaraju, G., Suresh, D., et al. (2015). Green synthesis of $\mathrm{CuO}$ nanoparticles using Gloriosa superba L. extract and their antibacterial activity. Journal of Talibah University of Science, 9, 7-12.

Nelson, D., Priscyla, D., Marcato, Gabriel, I. H. D., Oswaldo, L. A., \& Elisa, E. (2007). Antibacterial effect of silver nanoparticles produced by fungal process on textile fabrics and their effluent treatment. Journal of Biomedical Nanotechnology, 3, 203-208.
Nguyen, T. K. T., Maclean, N., \& Mahiddine, S. (2014). Mechanisms of nucleation and growth of nanoparticles in solution. Chemical Reviews, 114, 7610-7630.

Okoli, P. C., Adewuyi, G. O., Zhang, Q., Diagboya, P. N., \& Guo, Q. (2014). Mechanism of diakyl phthalates removal from aqeous solution using $\gamma$-cyclodextrin and starchbased polyurethane polymer adsorbents. Carbohydrates Polymers, 114, 440-449.

Penn, R. L., \& Banfield, J. F. (2004). Kinetics of orientated aggregation. Journal of Physical Chemistry B, 108, 12707-12712.

Prabakaran, M., Subha, K., Thennarasu, V., \& Merinal, S. (2012). Biosynthesis of silver nanoparticles using Sphaerulina albispiculata and evaluation of antibacterial activity. European Journal of Experimental Biology, 2(1), 297-303.

Rajesh, R., Raja, D. P., Rathi, J. M., \& Sahayaraj, K. (2012). Biosynthesis of silver nanoparticles using Ulva fasciata (Delile) ethyl acetate extract and its activity against Xanthomonas campestris pv. Malvacearum. Journal of Biopesticides, 5, 119-128.

Ray, P. C. (2010). Size and shape dependent second order nonlinear optical properties of nanomaterials and their application in biological and chemical sensing. Chemical Reviews, 110, 5332-5365.

Renquan, L., Dapeng, Y., Daxiang, C., Zhongyang, W., \& Lin, G. (2012). Egg white mediated green synthesis of silver nanoparticles with excellent biocompatibility and enhanced radiation effects on cancer cells. International Journal of Nanomedicine, 7, 2101-2107.

Ribeiro, C., Lee, E. J. H., Longo, E., \& Leite, E. R. (2005). A kinetic model to describe the nanocrystal growth by the oriented attachment mechanism. ChemPhysChem, 6, 690-695.

Roh, Y., Bai, J., Lauf, R. J., Mcmillan, A. D., Phelps, T. J., \& Rawn, C. J. (2001). Microbial synthesis of metal-substituted magnetites. Solid State Communications, 11, 529-534.

Sepideh, H., Seyedeh, M. G., Seyed, A. S., \& Soheila, S. (2012). Comparative study of silver nanoparticles produced by green methods. Iranian Journal of Biotechnology, 10(3), 191-197.

Sondi, I., \& Sondi, B. S. (2004). Silver nanoparticles as antimicrobial agent: A case study on E. coli as a model for Gram-negative bacteria. Journal of Colloid and Interface Science, 275(2004), 177-182.

Stohs, J., \& Bagchi, D. (1995). Oxidative mechanisms in the toxicity of metal ions. Free Radical Biology and Medicine, 18, 321-336.

Sujarania, S., Sironmani, T. A., \& Ramu, A. (2012). Synthesis, characterization and toxicity studies of Schiff bases [2-(2,2-diphenylethylimino) methyl)phenols] anchored silver nanoparticles. Digest Journal of Nanomaterials and Biostructures, 7(4), 1843-1857.

Swarnalatha, L., Christina, R., Shruti, R., \& Payas, B. (2012). Evaluation of in-vitro antidiabetic activity of Sphaeranthus amaranthoides silver nanoparticles. International Journal of Nanomaterials and Biostructures, 2(3), 25-29.

Ugwu, D. I., \& Okoro, U. C. (2014). Synthesis, characterization and antifungal activities of [4-methylphenylsulphonamido]-N-(pyridin-2-yl)acetamide derivatives. Medicinal Chemistry, 4(2), 330-333.

Wade, L. G. (2006). Organic chemistry (6th ed., pp. 523-532). USA: Prentice and Hall.

Yanjun, F., Zhenbo, X., Fengjiao, Y., Jian, S., Yewu, W., \& Wuzong, Z. (2012). Formation mechanism of hollow microspheres consisting of $\mathrm{ZnO}$ nanosheets. CrystEngComm, 14, 8615-8619.

Yijun, S., Deepa, J., Christopher, S., \& Kenneth, J. K. (2013). Alkyl and aromatic amines as digestive ripening/size focusing agents for gold nanoparticles. Nanomaterials, 3, 370-392.

Zhang, J., Huang, F., \& Lin, Z. (2010). Progress of nanocrystalline growth kinetics based on oriented attachment. Nanoscale, 2, 18-34. 